\title{
Cinsiyete Göre Yeme Farkındalığı Düzeyinin İncelenmesi: Bir Meta-Analiz Çalışması
}

\author{
Examination of the Mindful Eating Level by Gender: A Meta-Analysis Study
}

\author{
Hakan BOR ${ }^{1}$
}

\begin{abstract}
ÖZ
$\mathrm{Bu}$ araştırmanın amacı, cinsiyetlere göre yeme farkındalığı düzeyinin farklılık gösterip göstermediğini tespit edecek bir meta-analiz çalışması yürütmektir. Etki büyüklüklerini belirlemek için bu araştırmada Cohen's d olarak tanınan "Standardize Ortalamalar Farkı (SOF)" yönteminden faydalanılmıștır. Ayrıca yayın yanlılığını tespit etmek için "Orwin Güvenli N Sayıs1, Duval-Tweedie'nin Kırp-Doldur Yöntemi, Egger Regresyon Testi ve Huni Grafiği yöntemleri" kullanılmış ve yapılan bu araştırmada yayın yanlılığı olmadığ1 belirlenmiştir. Araştırma kapsamında yeme farkındalığı düzeyi konusu üzerinde yapılan alan yazın taramasında Türkiye evreni içinde 2016-2021 yılları arasında yürütülmüş olan 27 çalışmaya ulaşılmıştır. Dahil edilme ölçütleri doğrultusunda 12'si makale ve 4'ü tez olmak üzere 16 çalışma araştırmada incelenmiștir. Araştırmanın çalıșma grubu 3084'ü $(\% 36,8)$ erkek ve 5296'sı $(\% 63,2)$ kadın olmak üzere toplam 8380 kişiden oluşmaktadır. Araştırmada incelenen çalışmaların heterojen bir dağılım gösterdiği belirlenmiştir $\left(\mathrm{Q}=51,355, \mathrm{p}=0,000<0,01 ; \mathrm{I}^{2}=70,79\right)$. Rastgele etkiler modeline göre araştırma sonucunda, kadınların yeme farkındalığı düzeyinin erkeklere kıyasla daha yüksek olduğu tespit edilmesine rağmen bu sonuç istatistiksel olarak önemsiz düzeydedir (Cohen's $\mathrm{d}=0,020)$. Bunun yanında moderatör analizi yöntemiyle cinsiyete göre yeme farkındalığı düzeyi, örneklem alt gruplarına (ergen/yetişkin) göre yeniden değerlendirilmiş, moderatör analizi sonucunda yeme farkındalığ 1 düzeyinin ergen ve yetişkin örneklem grupları arasında istatiksel olarak anlamlı bir şekilde farklılaşmadığı belirlenmiştir $\quad\left(\mathrm{Q}_{\mathrm{b}}=0,001\right.$, $\mathrm{p}=0,978>0,05)$. Araştırma sonuçları var olan yeme farkındalığı literatürü doğrultusunda tartışılmıştır.
\end{abstract}

Anahtar Kelimeler: Cinsiyet, Meta Analiz, Yeme Farkındalığı.

\begin{abstract}
This research's aim is to perform a meta-analysis to see if the level of mindful eating varies by gender. The effect sizes were calculated utilizing "Standardized Mean Difference (SOF)", a Cohen's d analysis. Also, the "Orwin Fail-Safe N Number, Duval-Trim Tweedie's and Fill Method, Egger Regression Test and Funnel Plot method" were employed to look for publication bias and it was identified there wasn't a publication bias in this research. Within the scope of the research, through the literature review about the mindful eating level, 27 studies conducted between 2016-2021 in Turkey were reached. In line with the inclusion criteria, 16 studies, 12 of which were articles and 4 of which were thesis, were examined in the research. The research's study group consisted of 8380 persons, with 3084 (36.7\%) men and 5296 (63.2\%) women. The papers examined in the analysis were found to have a heterogeneous distribution $(\mathrm{Q}=51.355$, $\left.\mathrm{p}=0.000<0.01 ; \quad \mathrm{I}^{2}=70.79\right)$. Despite the fact that women's levels of mindful eating were greater than men's in the random effects model, this difference was statistically insignificant (Cohen's $\mathrm{d}=0.020$ ). Furthermore, using the moderator analysis method, the level of mindful eating was re-evaluated according to the sample subgroups (adolescent/adult) and after the moderator analysis it was revealed that there was no statistically significant difference on mindful eating level between the adolescent and adult sample groups $(\mathrm{Qb}=0.001, \mathrm{p}=0.978>0.05)$. Findings of the research were discussed in the light of existing mindful eating literature.
\end{abstract}

Keywords: Gender, Meta Analysis, Mindful Eating.

\footnotetext{
${ }^{1}$ Arș. Gör. Hakan BOR, Beslenme ve Diyetetik, Gümüșhane Üniversitesi Sağlık Bilimleri Fakültesi Beslenme ve Diyetetik Bölümü, hakanbor2009@hotmail.com, ORCID: 0000-0001-5430-4753

İletişim / Corresponding Author:

Geliş Tarihi / Received:

02.10 .2021

hakanbor2009@hotmail.com

Kabul Tarihi/Accepted

27.12.2021
} 


\section{GíRIŞ}

Obezite ve fazla kilo önemli toplumsal problemlerdir. Epidemiyolojik verilere göre, aşırı kilo ve obezite ile ilgili sorunlar dünya çapında endişe verici bir şekilde artmaya devam etmektedir. ${ }^{1}{ }^{2}$ Așırı kilonun ve obezitenin ortaya çıkışından ise temel olarak fiziksel hareketsizlik, yiyeceklerin aşırı tüketimi ve genetik gibi çeşitli nedenlerin sorumlu olduğu rapor edilmiştir. ${ }^{3}$ Bunun yanında son yıllarda yeme farkındalığı, aşırı kilo ve obezitenin temel sebeplerden biri olan yiyeceklerin aşırı tüketimine yol açan duygusal olaylara yanit olarak yemek yeme, aşererek yemek yeme, aşırı yemek yeme ve kontrolünü kaybederek yemek yeme gibi bazı uygun olmayan yeme davranışlarını tedavi etmenin potansiyel bir yolu olarak dikkate alınmış ve incelenmiştir. ${ }^{4}$

Duygusal, kontrol eksikliği hissinin eşlik ettiği aşırı yemek yeme ve bireyin kendi vücut ağırlığını kontrol etmeyi ve yönetmeyi amaçlayan kısıtlayıcı yemek yeme davranışları, sırasıyla açlık ve tokluk duygularından bağımsız olarak daha çok duygusal uyaranlara dayalı bir şekilde besin tüketimi ile karakterize edilen sorunlu yeme davranışlarıdır. ${ }^{5-7}$ Genel olarak bu problemli yemek yeme davranışları, doğal ve sezgisel yeme kaybına, gerçek açlık veya tokluk duygusunun ayırt edilebilmesinde zorluklara yol açmaktadır. ${ }^{5,8}$ Ancak bu durumun yeme farkındalığı teknikleri yardımıyla tedavi edilebileceği ve restore edilebileceği görülmüştür. ${ }^{9,}, 10$

$\mathrm{Bu}$ nedenle yeme farkındalığ 1 , mevcut güncel tedavileri desteklemek için giderek daha fazla kullanılmaktadır. ${ }^{4,11}$

Yeme farkındalığı kavramı, vücudun fiziksel ihtiyaçlarını ve bu ihtiyaçlarla ilişkili duygularını tatmin etmek amaciyla farkındalıklı bir şekilde yemek yemeyi ve kontrolsüzce yemek yeme yerine yemek yerken sezgisel olarak bedensel hisselere odaklanarak yemek yemeyi ifade etmektedir. $^{12,13}$

Bilimsel bağlamda kullanılan farkındalık terimi, mevcut deneyime dair bütün bir iç ve dış duruşu yansitan farklı tutum ve davranışları kapsamaktadır. Bilimsel söylem içinde bu nedenle çoğunlukla çok yönlü bir yapı olarak kavramsallaştırılmıştır. ${ }^{14}$ Yapının çok yönlü doğası üzerinde bir fikir birliği olsa da rapor edilen boyutlarının sayısı farklı değerlendirmelere göre değişmektedir. Örneğin; Bishop (2004) farkındalığ 1 iki boyutla kavramsallaştırmıştır: 1) Şimdiki âna dair farkındalık ve dikkat 2) Yaşanan deneyime karşı ön yargılı olmayan ve kabul eden bir tutum. ${ }^{15}$ Baer ve ark. (2006) ise farkındalığı beş boyutta tanımlamıştır: 1)Deneyim farkındalığına atıfta bulunan gözlemleme/fark etme, 2)Deneyimin tanımlanması, 3)Farkındalıkla hareket etmek, 4)Deneyimi yargılamamak, 5)İçsel deneyime tepkisizlik. ${ }^{16}$ Ek olarak Köse ve ark. (2016) yeme farkındalığını 7 boyutta tanımlamıştır: 1)Disinhibisyon, 2)Yeme Kontrolü, 3) Farkındalık, 4) Duygusal Yeme, 5)Yeme Disiplini, 6)Odaklanma ve 7)Enterferans. ${ }^{17}$

$\mathrm{Bu}$ araştırmanın amacı, cinsiyetlere göre yeme farkındalığ 1 düzeyinin farklılık gösterip göstermediğini tespit edecek bir meta-analiz çalışması yürütmektir. $\mathrm{Bu}$ amaç doğrultusunda Türkiye evreninde yapılmış ve Köse ve ark. (2016) tarafindan geliştirilmiş yeme farkındalığı ölçeğinin (YFÖ-30) kullanıldı ̆̆ 26 çalışma içerisinden çalışmaya dâhil edilmeye uygun olan 16 çalışmanın sonuçları bir araya getirilerek, meta analiz yöntemiyle cinsiyete göre yeme farkındalığ düzeyi incelenmiştir. ${ }^{17}$

\section{MATERYAL VE METOT}

$\mathrm{Bu}$ çalışma meta analiz yöntemi kullanılarak hazırlanmıştır. Akgöz ve ark. (2004) tarafindan meta analiz yöntemi sabit bir konu hakkında yürütülmüş, her biri farklı olan çalışma bulgularının istatistiksel olarak toplu bir şsekilde değerlendirilmesi ve incelenmesi olarak tanımlanmıştır. ${ }^{18}$ Ayrıca meta analiz çalışmasına dahil edilecek 
çalışmalarda aynı bağımlı değişkenin (ölçeğin) kullanılmasının, kanıta dayalı olan ve güven aralıklarını göz önünde tutan çalışmalar için zorunlu olduğu bildirilmiştir. ${ }^{19}$ $\mathrm{Bu}$ nedenle temel olarak bu çalışmaya eklenen araştırmalarda Köse ve ark. (2016) tarafından geliştirilmiş olan YFÖ-30 ölçeğinin kullanılması araştırmalarda ilk şart olarak aranmıştır. $^{17}$

\section{Literatür Taraması}

Yapılan bu çalışmanın veri kaynağını Türkiye evreninde YFÖ-30 ölçeği kullanılarak yeme farkındalığı konusu üzerinde yapılmış makale ve lisansüstü tezler teşkil etmektedir. Google Akademik Veri Tabanı ve YÖK Tez Merkezi üzerinde yapılan taramalarda ölçeğin geliştirildiği 2016 y1lından 2021 yılına kadar YFÖ-30 ölçeğinin kullanıldığı $27 \quad$ (19 makale ve 8 tez) çalışmanın var olduğu tespit edilmiştir. Ancak tüm çalışmalar dahil edilme şartlarını taşımadığından bu şartların tamamını taşıyan 16 (12 makale ve 4 tez) çalışmanın sonuçları bu meta analiz çalışmasında bir araya getirilip incelenmiştir. İlgili araştırmalara ulaşabilmek için "yeme farkındalığı","mindful eating", "yeme farkındalığı ölçeği (YFÖ-30)" ve YFÖ-30 kelimeleri kullanılmıştır.

\section{Dahil Edilme Şartları}

Meta analiz çalışmasına dahil edilirken araştırmalarda aranan şartlar:

1. Google Akademik Veri Tabanı üzerinden ulaşılan makalelerin hakemli bilimsel yayınlarda yayımlanmış olması

2. YÖK Tez Merkezi üzerinden ulaşılan lisansüstü tezlerin tam metin halinin bulunmas1

3. Araştırmaların etki büyüklüklerini hesaplamak için gerekli verileri içermesi

4. Araştırmaların Türkiye evreni içerisindeki örneklemler üzerinde yapılmış olması

5. Araştırmalarda yeme farkındalığını ölçmek için YFÖ-30 ölçeğinin kullanılmış olması

6. Cinsiyete göre yeme farkındalığ düzeylerinin araştırma içerisinde verilmiş olmas1

7. Türkçe veya İngilizce dilinde yayımlanmış olmas1
Sonuç olarak alan yazın taranmış ve dahil edilme şartlarını taşıyan 16 araştırma çalışma kapsamına alınmıştır. Bu 16 çalışmadan elde edilen sonuç verileri üzerinden cinsiyete göre yeme farkındalığı düzeyindeki değişim meta analiz yöntemiyle incelenmiştir.

\section{Çalışmanın Kodlanması}

$\mathrm{Bu}$ meta analiz çalışmasında etki büyüklüğünü belirlemek için bir diğer adı Cohen's d olan "Standardize Ortalamalar Fark1 (SOF)" yöntemi kullanılmıştır. Araştırmaların etki büyüklüklerini tespit etmek için erkek ve kadın örneklem büyüklüğü sayılarından, yeme farkındalığı ortalama puanlarından ve standart sapma değerlerinden faydalanılmıştır. Araştırmalarda yer alan iki cinsiyetten erkek $=0, \quad$ kadın=1 olarak kodlanmıştır. Çalışmada pozitif etki büyüklüğü kadınların, negatif etki büyüklüğü erkeklerin yeme farkındalığı düzeylerinin daha yükssek olduğunu ifade etmektedir. Meta analizdeki araştırmaların üzerinde yapıldığı ergen ve yetişkin örneklemleri moderatör değişskenler olarak değerlendirilmiştir.

\section{Çalışmaya Dahil Edilmiş Olan Araștırmaların Genel Özellikleri}

Çalışmaya dahil edilmiş olan 16 çalışma 2016-2021 tarihleri arasında yapılmıştır. Cinsiyet bakımından çalışmaya dahil edilen araştırmalar değerlendirildiğinde çalışma gruplar1 toplamda 3084'ü erkek ve 5296's1 kadın olmak üzere toplam 8380 kişiden oluşmaktadır. Araştırmaların 12'si makale ve 4'ü lisansüstü tezdir. Ayrıca araştırmaların

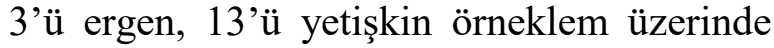
yapılmıştır. Çalışmaya dahil edilen araştırmaların tamamında Köse ve ark. (2016) tarafından geliştirilen yeme farkındalığ ölçeği (YFÖ-30) kullanılmıştır. ${ }^{17}$

\section{Verilerin Analizi}

Meta analiz yönteminde temel olarak yayın yanlılığı, etki büyüklüğü ve heterojenlik testi sonuçları kullanılmaktadır. Araştırmaların etki büyüklüklerinin belirlenmesinde "Comprehensive Meta Analysis (CMA) (Version 3.0)" analiz programindan faydalanılmıştır. Etki büyüklükleri, sabit ve 
rastgele etkiler modellerine göre tespit edilmiş ve bu çalışmaya uygun olarak rastgele etki modeline göre incelenmiştir. ${ }^{20}$ Buna ek olarak çalışmadaki araştırmaların etki büyüklüklerinin heterojen dağılım gösterdiği $Q$ ve $\mathrm{I}^{2}$ istatistiği ile tespit edilmiştir.

\section{Yayın Yanlılığı}

$\mathrm{Bu}$ meta analiz çalışmasına dahil edilmiş olan araştırmalarda yayın yanlılığı olup olmadığ1 'Duval-Tweedie'nin Kırp-Doldur Yöntemi, Orwin Güvenli N Sayısı, Egger Regresyon Testi ve Huni Grafiğì" kullanılarak belirlenmiştir. ${ }^{21}$

Tablo 1. Araştırmaya Dahil Edilmiş Olan Çalışmaların Genel Özellikleri

\begin{tabular}{|c|c|c|c|c|c|}
\hline \multirow[b]{2}{*}{ Çalışma } & \multirow[b]{2}{*}{ Çalışma Türü } & \multirow[b]{2}{*}{$\begin{array}{l}\text { Kullanılan } \\
\text { Ölçek }\end{array}$} & \multicolumn{3}{|c|}{ Örneklem Sayısı } \\
\hline & & & $\begin{array}{l}\text { Erkek } \\
\text { Katılımcı } \\
\text { Sayısı }\end{array}$ & $\begin{array}{l}\text { Kadın Katılımcı } \\
\text { Sayısı }\end{array}$ & Toplam \\
\hline $\begin{array}{l}\text { Köse, Tayfur, } \\
\text { Birincioğlu, Dönmez, } \\
2016^{17}\end{array}$ & Makale & YFÖ-30 & 72 & 246 & 318 \\
\hline Akpinar, $2019^{22}$ & Tez (Yüksek Lisans) & YFÖ-30 & 29 & 176 & 205 \\
\hline Durukan, Gül, $2019^{23}$ & Makale & YFÖ-30 & 143 & 455 & 598 \\
\hline Köse, Çıplak, $2019^{24}$ & Makale & YFÖ-30 & 252 & 116 & 368 \\
\hline Üstündağ, $2020^{25}$ & Tez (Yüksek Lisans) & YFÖ-30 & 118 & 232 & 350 \\
\hline $\begin{array}{l}\text { Karataş, Müftüoğlu, } \\
2020^{26}\end{array}$ & Makale & YFÖ-30 & 57 & 219 & 276 \\
\hline $\begin{array}{l}\text { Barışkan, Karakoç } \\
\text { Kumsar, } 2020^{27} \\
\end{array}$ & Makale & YFÖ-30 & 156 & 816 & 972 \\
\hline Subay Orbatu, $2020^{28}$ & Makale & YFÖ-30 & 896 & 1241 & 2137 \\
\hline Boyraz, $2020^{29}$ & Tez (Yüksek Lisans) & YFÖ-30 & 301 & 313 & 614 \\
\hline $\begin{array}{l}\text { Çakaroğlu, Ömür, } \\
\text { Arslan, } 2020^{30}\end{array}$ & Makale & YFÖ-30 & 156 & 206 & 362 \\
\hline Köse, Çıplak, $2020^{31}$ & Makale & YFÖ-30 & 260 & 140 & 400 \\
\hline Saygin, $2021^{32}$ & Tez (Yüksek Lisans) & YFÖ-30 & 16 & 287 & 303 \\
\hline Özkan, Bilici, $2021^{33}$ & Makale & YFÖ-30 & 68 & 182 & 250 \\
\hline Kes, Çiçek, $2021^{34}$ & Makale & YFÖ-30 & 366 & 434 & 800 \\
\hline $\begin{array}{l}\text { Demirer, Yardımc1, } \\
2021^{35}\end{array}$ & Makale & YFÖ-30 & 92 & 105 & 197 \\
\hline Uçar, Türker, $2021^{36}$ & Makale & YFÖ-30 & 102 & 128 & 230 \\
\hline
\end{tabular}

\section{BULGULAR VE TARTIŞMA}

Meta analiz çalışmanın bu kısmında çalıșmaya dahil edilmiş olan araştırmalarda yayın yanlılığının olup olmadığının belirlenmesinde kullanilan analizlerin sonuçları, araştırmaların etki büyüklüklerine dair orman grafiği, alt grup analizi sonucunda elde edilen veriler ve heterojenlik testi sonuçları gösterilmiştir.
Çalışma dâhilindeki araştırmalarda yayın yanlılığının olup olmadığına ilişkin olarak yapilan "Duval-Tweedie'nin Kirp-Doldur Yöntemi, Orwin Güvenli N Sayısı, Egger Regresyon Testi ve Huni Grafiği" sonuçları aşağıda verilmiştir.

Çalışmaya dahil edilmiş olan çalışmaların yayın yanlılığına dair sonuçlar Tablo 2'de verilmiştir. 
Tablo 2. "Duval-Tweedie’nin Kırp-Doldur Yöntemi, Orwin Güvenli N Sayısı ve Egger Regresyon Testi”" Yayın Yanlıı̆̆ı Analiz Verileri

\begin{tabular}{|c|c|c|c|c|}
\hline \multirow{2}{*}{$\begin{array}{l}\text { Dahil } \\
\text { Edilen } \\
\text { Çalışma } \\
\text { Sayısı }\end{array}$} & \multirow{2}{*}{$\begin{array}{l}\text { “Orwin’in Güvenli N Sayısı } \\
\text { Önemsiz SOF için Gerekli } \\
\text { Çalışma Sayısı” }\end{array}$} & \multicolumn{2}{|c|}{$\begin{array}{l}\text { "Duval ve Tweedie'nin Kırp ve } \\
\text { Doldur Yöntemi" }\end{array}$} & \multirow{2}{*}{ Egger Testi } \\
\hline & & $\begin{array}{l}\text { Kırpılan } \\
\text { Çalışma }\end{array}$ & $\begin{array}{l}\text { SOF } \\
\text { Gözlenen } \\
\text { (Doldurulan) }\end{array}$ & \\
\hline 16 & $0,01 \mathrm{SOF}$ için 93 & & $0,068(0,068)$ & $\mathrm{p}=0,071$ (çift kuyruk) \\
\hline
\end{tabular}

Tablo 2'de yer aldığ 1 üzere "Orwin'in Güvenli N sayısı (Orwin's Fail-Safe N)" değeri hesaplama sonucunda 93 olarak bulunmuştur. Buna bağlı olarak çalışmanın etki büyüklüğünü neredeyse sıfır olan 0,01 düzeyine çekebilmek için gerekli ek çalışma sayısı 93 'tür. Bu sayı çalışmaya dahil edilmiş olan araştırma sayısının yaklaşık 6 katıdır. Bu çalışma için yeme farkındalığ konusunda yapılan tüm araştırmalar taranmış ve şartları sağlayan 16 araştırmanın tamamı çalışmada incelenmiştir. $\mathrm{Bu}$ nedenle çalışma etki büyüklüğünü farksız düzeye çekebilecek ek 93 araştırmaya ihtiyaç duyulması, bu meta analiz çalışmasının yayın yanlılığının olmadığının önemli bir göstergesidir. "Duval-
Tweedie'nin Kırp-Doldur Yöntemi” nin sonucunda ise çalışmanın etki büyüklügünü̈ değiştirecek ek emsal bir çalışmaya gerek olmadığı görülmüştür. Bu sonuç da bu meta analiz çalışmasının etki büyüklügünün güvenilir olduğunu göstermektedir. Son olarak Egger Testi sonucunda elde edilen $\mathrm{p}=0,071 \quad(\mathrm{p}>0,05) \quad$ değerinin istatistiksel olarak anlamlı olmaması da çalışmada yayın yanlılı̆̆ının olmadığını ayrıca ortaya koymaktadır.

Şekil 1'de çalışmanın yayın yanlılığı durumunu görsel olarak ifade eden "Huni Saçılım Grafiğì" verilmiştir.

Funnel Plot of Standard Error by Std diff in means

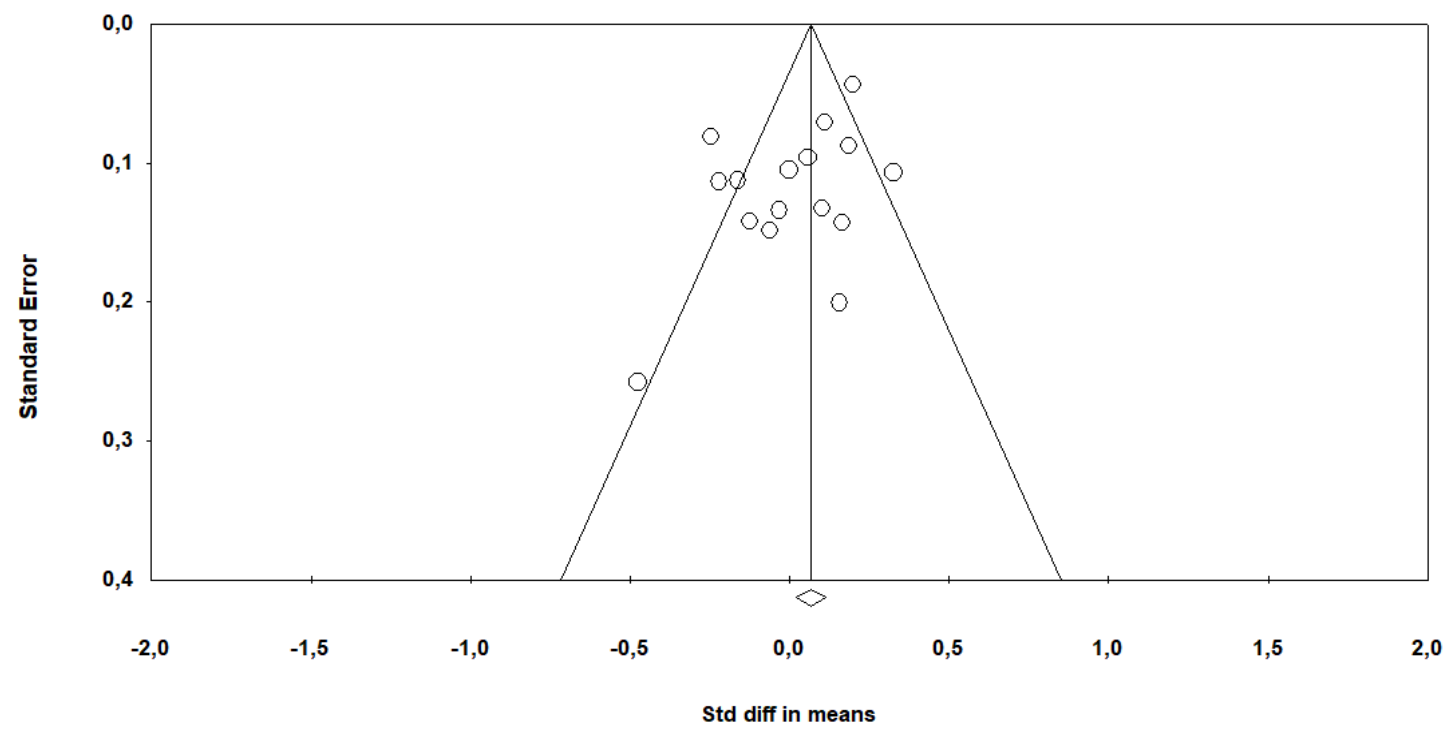

Şekil 1. Meta Analiz Huni Saçılım Grafiği 
Şekilde görüldügü üzere çalışma içindeki 16 araştırma birleştirilmiş etki büyüklüğü orta çizgisinin her iki tarafina yaklaşı simetrik dağılım göstermiş, orta üst bölgede toplanıp, birleştirilmiş etki büyüklügü çizgisine yakın bir konum almışlardır. Bu test sonucunda elde edilen yayın saçılım örneğine dayanarak bu çalışmada yayın yanlılığının bulunmadığı söylenebilir.

\section{Çalışmaya Dahil Edilen Araştırmaların Orman Grafiği}

Şekil 2'de çalışmadaki 16 araştırmayı toplu bir şekilde içeren orman grafiği (forest plot) verilmiştir.

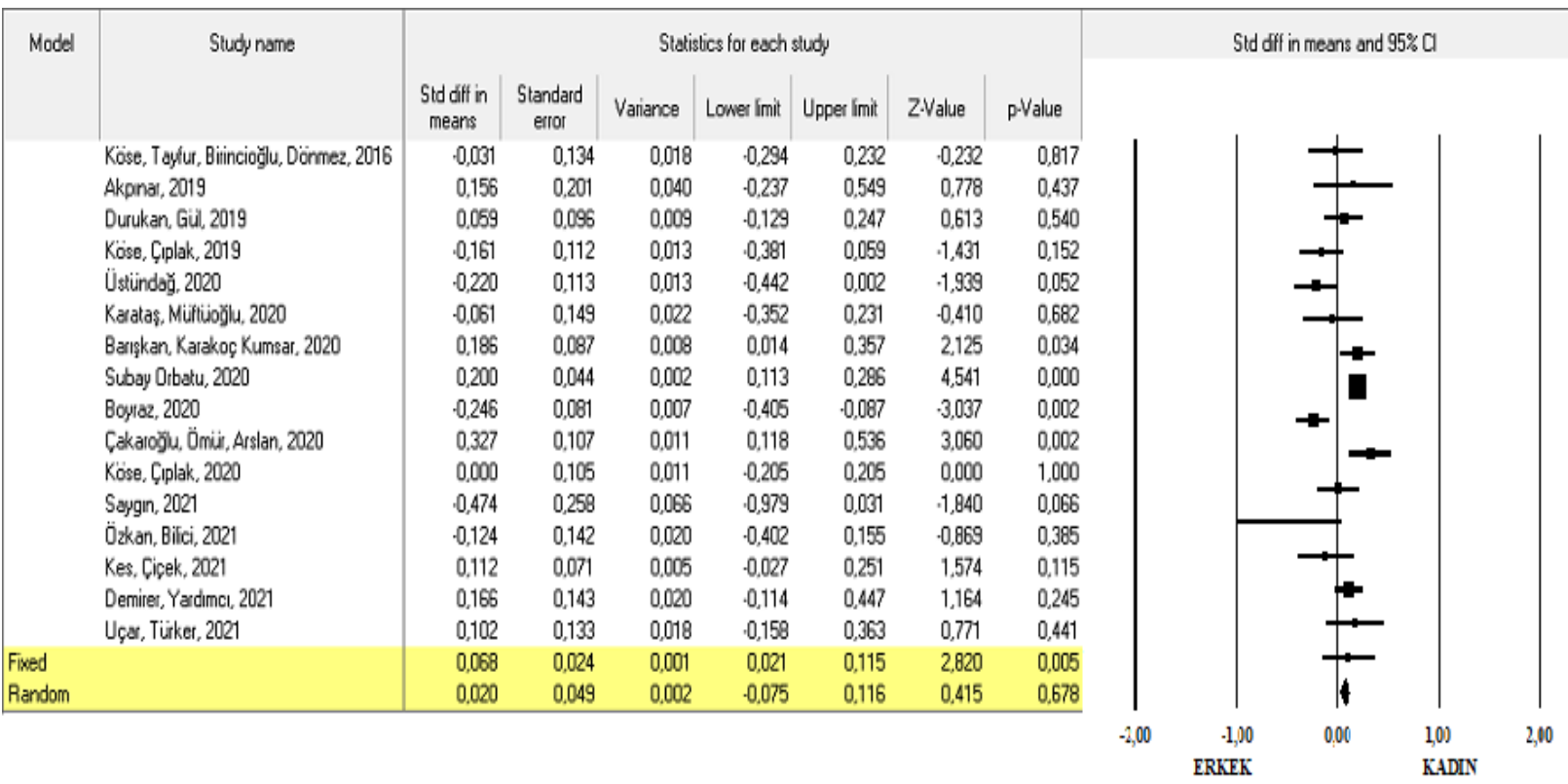

Şekil 2. Çalışmada İncelenen Araştırmaların Orman Grafiği

Şekil 2 gözden geçirildiğinde yeme farkındalığ 1 bakımından kadınlar lehine bir farkın oluştuğu ancak bu farkın küçük bir düzeyde olduğu görülmektedir.

\section{Cinsiyetle İlişkili Etki Büyüklüğü Analiz Verileri}

Yapılan bu meta analiz çalışmasının temel amacı cinsiyete göre yeme farkındalığı düzeyinde anlamlı bir farklılı̆̆ın olup olmadığının tespit edilmesidir. Tablo 3 'te çalışmaya dahil edilen araştırmaların etki büyüklüklerinin heterojenlik testi sonucu, sabit etki ve rastgele etki modelleri kullanılarak elde edilen değerlendirme sonuçları gösterilmiştir.

Tablo 3. Heterojenlik Testi ve Etki Büyüklüğü Analiz Verileri

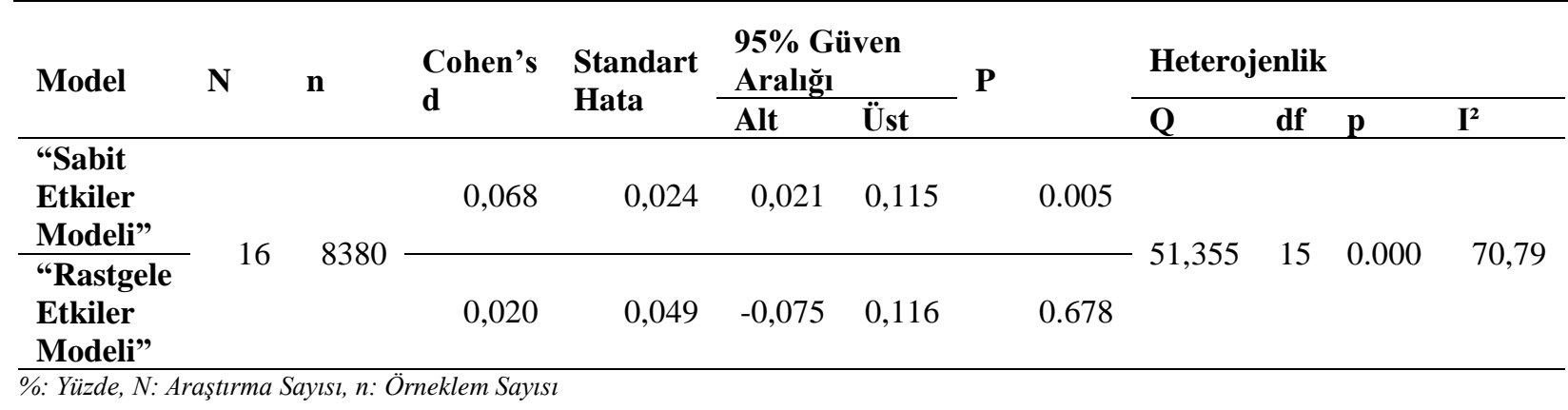


Tablo 3'te yer alan inceleme sonuçlarına göre $\mathrm{Q}(\mathrm{sd}=16)$ değerinin 51,355 olduğu görülmektedir. Ayrıca bu hesaplamayı temsil eden $p=0,000(p<0,05)$ olarak bulunduğu için etki büyüklüklerinin yapısının heterojen olduğu belirlenmiştir. Ayrıca etki büyüklügüule ilişkili toplam varyansın oranını ifade eden $\mathrm{I}^{2}$, Q hesaplamasinın tamamlayıcıs1 olarak ortaya konmuş ve heterojenliğe dair daha net sonuçlar verdiği rapor edilmiştir. ${ }^{37}$ Ek olarak $\mathrm{I}^{2}$, Q değerinde olduğu gibi araştırma sayısından etkilenmemektedir. Çalışma sonucunda elde edilen $\mathrm{I}^{2}$ değeri $\% 70,79$ oranıyla \%50'lik değerin üzerinde çıkarak, çalışmanın orta düzeyde heterojen

\section{Moderatör Analiz}

Ergen bireylerin oluşturduğu örneklemler üzerinde yapılmış olan araştırmaların etki büyüklüğünün $\quad 0,019 \quad([-0,290 ; 0,328]$, $\mathrm{p}=0,904>0,05), \quad$ yetişkin bireylerin oluşturduğu örneklemler üzerinde yapılmış olan araştırmaların etki büyüklüğünün 0,024 $([-0,073 ; 0,121], \quad \mathrm{p}=0,632>0,05) \quad$ olduğu anlaşılmaktadır. Bu sonuçlara göre her iki grupta da yeme farkındalığı düzeyinin kadınlar lehine az da olsa daha yüksek olduğu görülmektedir. Ancak çalışmalar arası varyans, örneklem grubu moderatörü bakımından istatistiksel olarak anlamlı çıkmamıştır $\left(\mathrm{Q}_{\mathrm{b}}=0,001, \mathrm{p}=0,978>0,05\right) . \mathrm{Bu}$ sonuca göre araştırmaların üzerinde yapıldığ örneklem gruplarının yeme farkındalığ üzerindeki cinsiyetin etki büyüklüğünü anlamlı bir derecede etkilemediği tespit edilmiştir.

Literatürde yapılan alan taramasında bu çalışma sonuçlarının cinsiyet göre yeme farkındalığı düzeyini araştıran bazı çalışmalarla desteklenirken, bazı çalışmalarda ise ters yönde sonuçlara varıldığı görülmüştür. $\mathrm{Bu}$ araştırmayla benzer sonuçlara ulaşmış olan çalışmalardan bazıları şunlardır; ilk olarak 260 erkek ve 140 kadın üniversite öğrencisi üzerinde yeme farkındalığ düzeyinin ölçüldüğü bir araştırmada cinsiyetler arası yeme farkındalığı puanları bakımından anlamlı bir farklılık bulunmadığ olduğunu göstermektedir. ${ }^{38}$ Çalışmanın heterojen olduğu bu hesaplamalar yardımıyla tespit edildikten sonra "rastgele etkiler modeline" karşılık gelen "ortalama etki büyüklüğü" değeri yorumlanmıştır. Rastgele etkiler modeli hesaplamasına karşılık gelen ortalama etki büyüklüğünün üst sınırının 0,116 , alt sinırının $-0,075$, standart hatasının 0,049 ve etki büyüklüğünün 0,020 olduğu belirlenmiştir. Ancak ortalama etki büyüklüğünün 0,20 'den daha düşük olmasından ötürü Cohen siniflandırması içinde düşük düzeyin altında yer aldığı yani önemsiz bir etkiyi temsil ettiği görülmüştür. ${ }^{39}$

görülmüştür $(\mathrm{p}=0.682) .{ }^{31}$ Yeme farkındalığ1 düzeyini 366 erkek ve 434 kadın üniversite öğrencisi üzerinde araştıran bir başka çalışmada ise kadınlar lehine yeme farkındalığı puanlarının erkeklere kıyasla daha yüksek olmasına rağmen yeme farkındalığı düzeyinin cinsiyete göre farklılık göstermediği bildirilmiştir $(\mathrm{p}>0.05) .{ }^{34}$ Son olarak liseli 102 erkek ve 128 k1z öğrenciden oluşan bir örneklem grubu üzerinde yapılan bir çalışmada da yeme farkındalığı düzeyinin kadınlar lehine olmasına rağmen, cinsiyetin yeme farkındalığı düzeyini istatistiksel olarak anlamlı bir şekilde etkilemediği rapor edilmiştir $(p=0,448) .{ }^{36}$ Diğer yandan bu çalışmayla aksi yönde sonuçlara ulaşan çalışmalardan bazıları ise şunlardır; Orbatu (2020) 896 erkek ve 1241 kız lise öğrencisi üzerinde yaptığ 1 bir çalışma sonucunda kız yeme farkındalığ 1 puan ortalamasının $(98,18 \pm 14,94)$, erkek yeme farkındalığ ortalamasindan $\quad(95,21 \pm 14,80) \quad$ yüksek olduğunu ve bu sonucun istatistiksel olarak anlamlı olduğu tespit etmiştir $(p=0.02){ }^{28}$ Boyraz (2020) ise 301 erkek ve $313 \mathrm{klz}$ lise öğrencisi üzerinde yaptığ 1 araştırma sonucunda erkek lise öğrencilerinin yeme farkındalığ1 puan ortalamasının $(94,98 \pm 12,96), k 1 z$ lise öğrencilerinin yeme farkındalığ 1 puan ortalamasindan $(91,69 \pm 13,75)$ istatistiksel olarak anlamlı bir şekilde daha yüksek olduğunu rapor etmiştir $(\mathrm{p}=0.002){ }^{29}$ 


\section{SONUÇ VE ÖNERILER}

$\mathrm{Bu}$ meta analiz çalışması, Türkiye örnekleminde yeme farkındalığı düzeyinde cinsiyete (kadın/erkek) göre anlamlı bir farklılaşma olup olmadığını tespit etmek ve meydana gelebilecek farklılığın ergen ve yetişkin örneklem alt grupları bakımından moderatör etkisini belirlemek amaciyla yürütülmüştür.

Yapılan taramalarda, Türkiye'de 20162021 yıllarında YFÖ-30 ölçeği kullanılarak yeme farkındalığı konusu üzerine yapılan 27 araştırma belirlenmiştir. $\mathrm{Bu}$ araştırmaların çalışma içine alınmasında bazı kriterler konulmuş ve bu kriterler kapsamında 12'si makale, 4'ü tez toplam 16 araştırma çalışmaya dahil edilmiştir. Çalışmaya dahil edilen araştırmaların örneklem büyüklüğü toplamda 8380 bireydir. Örneklemin; 3084'ü $(\% 36,8)$ erkek ve 5296'sı $(\% 63,2)$ kadın gönüllü katılımcıdan oluşmaktadır. Araştırma içindeki bu çalışmalarda yayın yanlılığının olup olmadığını tespit etmek amaciyla "DuvalTweedie'nin Kırp-Doldur Yöntemi, Orwin Güvenli N Sayısı, Egger Regresyon Testi ve Huni Grafiği” yöntemlerinden faydalanılmıştır. Bu yöntemlerle elde edilen sonuçlar 1şı̆̆ında da yayın yanlılığının mevcut olmadığı görülmüştür. Ek olarak ortalama etki büyüklüğünü, heterojenliğini, anlamlı bir farkın olup olmadığını ve farkın hangi cinsiyet lehine olduğunu belirlemek için de "Cohen's $\mathrm{d}, \mathrm{CI}, \mathrm{Q}, \mathrm{p}$ ve $\mathrm{I}^{2}$ " temel analiz yöntemleri kullanılmıştır. Sonuç olarak araştırma verilerinin heterojenlik testi sonuçları, dağılımlarının heterojen olduğunu göstermiş $(\mathrm{Q}=51,355, \mathrm{p}<0,01)$ ve yapılan çalışmada dağılımların heterojen olduğu sonucuna uygun bir şekilde rastgele etkiler modeli tercih edilmiştir. Yeme farkındalığı düzeyi açısından etki büyüklüğü olarak 0,020'lik kadınlar lehine bir durumun mevcut olduğu belirlenmiştir. Ancak bu etki büyüklüğünün istatistiksel olarak anlamlı olmadığı görülmüştür.

Ek olarak moderatör analizi yardımıyla yeme farkındalığı düzeyinin iki alt örneklem grubuna (Ergen ve Yetişkin) göre değişip değişmediği araştırılmıştır. Moderatör analizi sonucunda, ergen ve yetişkin alt gruplarının etki büyüklüklerinin sırasıyla 0,019 ve 0,024 olduğu tespit edilmiştir. Ancak bu sonuçların alt örneklem gruplarının (Ergen ve Yetişkin) cinsiyete göre oluşturulan etki büyüklüklerini anlamlı bir şekilde etkilemediği belirlenmiştir $\left(\mathrm{Q}_{\mathrm{b}}=0,001, \mathrm{p}>0,05\right)$.

Sonuç olarak, bu sunulan çalışmanın meta analiz sonuçları yeme farkındalığı düzeyinin ne cinsiyet ne de moderatör alt gruplar olan ergen ve yetişkinler açısından istatistiksel olarak anlamlı bir şekilde farklılaşmadığını ortaya koymuştur. Daha açık bir anlatımla yeme farkındalığı düzeyinde cinsiyete göre kadınlar lehine ve moderatör alt gruplara göre ise yetişkin bireyler lehine bir etki büyüklüğünün var olduğundan bahsedebilmekle beraber, bu etki büyüklükleri küçük düzeyde olup dikkate alınabilecek düzeyde değildir. Diğer yandan gelecek yıllar için, bu konuda yapılacak yeni araştırmaların da Türkiye'deki cinsiyete göre yeme farkındalığı düzeyini bir meta analiz araştırması yöntemiyle ilk defa inceleyen bu veri setine eklenerek yeni meta analiz çalışmalarıyla bu durumun yıllar içinde anlamlı bir şekilde değişip değişmeyeceğinin gözlenmesi tavsiye edilmektir. Ayrica yeme farkındalığı düzeyinin bölgelerin gelişmişlik düzeyine göre değişip değişmediğini gösterebilecek daha kapsamlı yeni araştırmaların yapılması önerilmektedir. 


\section{KAYNAKLAR}

1. Arroyo-Johnson, C. and Mincey, K.D. (2016). "Obesity Epidemiology Worldwide". Gastroenterology Clinics of North America, 45 (4), 571-579.

2. Forster, M, Veerman, J.L, Barendregt, J.J. and Vos, T. (2011) "Cost-Effectiveness of Diet and Exercise Interventions to Reduce Overweight and Obesity". International Journal of Obesity, 35 (8), 1071-1078

3. Stern, J.S. and Kazaks, A. (2009). Obesity: A Reference Handbook. California: ABC-CLIO.

4. O'Reilly, G.A, Cook, L, Spruijt-Metz, D. and Black, D.S. (2014) "Mindfulness-Based Interventions for Obesity-Related Eating Behaviours: a Literature Review". Obesity Reviews, 15 (6), 453 461. https://doi.org/10.1111/obr.12156

5. Conceição, E.M, Utzinger, L.M. and Pisetsky, E.M. (2015) "Eating Disorders and Problematic Eating Behaviours Before and After Bariatric Surgery: Characterization, Assessment and Association with Treatment Outcomes". European Eating Disorders Review, 23 (6), 417-425.

6. Micanti, F, Iasevoli, F, Cucciniello, C, Costabile, R, Loiarro, G, Pecoraro, G, Pasanisi, F, Rossetti, G. and Galletta, D. (2017). "The Relationship Between Emotional Regulation and Eating Behaviour: a Multidimensional Analysis of Obesity Psychopathology". Eating and Weight Disorders-Studies on Anorexia, Bulimia and Obesity, 22 (1), 105-115.

7. Van Strien, T, Herman, C.P. and Verheijden, M.W. (2009) "Eating Style, Overeating, and Overweight in a Representative Dutch Sample. Does External Eating Play a Role?". Appetite, 52 (2), 380-387. https://doi.org/10.1016/j.appet.2008.11.010

8. Orcutt, M, Steffen, K. and Mitchell, J.E. (2017). Eating and Weight Disorders. In: Stewart Agras, W. and Robinson, A. (Ed.). The Oxford Handbook of Eating Disorders. 458-463. New York: Oxford University Press.

9. Kristeller, J, Wolever, R. and Sheets, V. (2014). "MindfulnessBased Eating Awareness Training (MB-EAT) for Binge Eating: A Randomized Clinical Trial". Mindfulness, 5 (3), 282-297.

10. Wnuk, S.M, Du, C.T, Van Exan, J, Wallwork, A, Warwick, K, Tremblay, L, Kowgier, M. and Sockalingam, S. (2018) "Mindfulness-Based Eating and Awareness Training for PostBariatric Surgery Patients: a Feasibility Pilot Study". Mindfulness, 9 (3), 949-960.

11. Ouwens, M.A, Schiffer, A.A, Visser, L.I, Raeijmaekers, N.J.C and Nyklíček, I. (2015). "Mindfulness and Eating Behaviour Styles in Morbidly Obese Males and Females". Appetite, 87 (2), 62-67.

12. Meier, B.P, Noll, S.W. and Molokwu, O.J. (2017). "The Sweet Life: The Effect of Mindful Chocolate Consumption on Mood". Appetite, 108 (1), 21-27.

13. Kristeller, J.L. and Wolever, R.Q. (2010). "Mindfulness-Based Eating Awareness Training for Treating Binge Eating Disorder: The Conceptual Foundation". Eating Disorders, 19 (1), 49-61.

14. Bergomi, C, Tschacher, W. and Kupper, Z. (2013). "The Assessment of Mindfulness with Self-Report Measures: Existing Scales and Open Issues". Mindfulness, 4 (3), 191-202.

15. Bishop, S.R, Lau, M, Shapiro, S, Carlson, L, Anderson, N.D, Carmody, J, Segal, Z.V, Abbey, S, Speca, M. and Velting, D. (2004). "Mindfulness: a Proposed Operational Definition". Clinical Psychology: Science and Practice, 11 (3), 230.

16. Baer, R.A, Smith, G.T, Hopkins, J, Krietemeyer, J. and Toney, L. (2006). "Using Self-Report Assessment Methods to Explore Facets of Mindfulness". Assessment, 13 (1), 27-45

17. Köse, G, Tayfur, M, Birincioğlu, İ. ve Dönmez, A. (2016) "Yeme Farkındalığı Ölçeği'ni Türkçe'ye Uyarlama Çalışması". Bilişsel Davranışçı Psikoterapi ve Araştırmalar Dergisi, 3 (1), $125-134$
18. Akgöz, S, Ercan, İ. ve İsmet, K. (2004). "Meta-Analizi". Uludağ Üniversitesi Tıp Fakültesi Dergisi, 30 (2), 107-112.

19. Turan, S. (2015). Uygulamada Araştırma Yöntemleri: Desen ve Analizi Bütünleştiren Yaklaşım. New York: Nobel Yayınevi.

20. Cumming, G. (2013). Understanding the New Statistics: Effect Sizes, Confidence Intervals, and Meta-Analysis. New York: Routledge.

21. Dinçer, S. (2014). "Eğitim Bilimlerinde Uygulamalı MetaAnaliz". Pegem Atıf İndeksi, 2014 (1), 1-133.

22. Akpınar, B. (2019). Obezite ve Diyabette Yeme Farkındalığı. Yüksek Lisans Tezi, İstanbul Okan Üniversitesi Sağlık Bilimleri Enstitüsü, İstanbul.

23. Durukan, A. and Gül, A. (2019). "Mindful eating: Differences of Generations and Relationship of Mindful eating with BMI". International Journal of Gastronomy and Food Science, 18 (1), 100-172.

24. Köse, G. and Çıplak, M.E. (2019). "Does Mindful Eating have a Relationship with Gender, Body Mass Index and Health Promoting Lifestyle?". Progress in Nutrition, 22 (2), 528-535.

25. Üstündağ, E.G. (2020). Spor Salonunda Spor Yapan Bireylerde Yeme Farkındalığı ile Ortoreksiya Nervoza Belirtileri Arasındaki İlișkinin İncelenmesi. Yüksek Lisans Tezi, Çağ Üniversitesi Sosyal Bilimler Enstitüsü, Mersin.

26. Müftüoğlu, S. ve Karataş, Y.F. (2020). "Sağlık Yüksekokulu Öğrencilerinin Yeme Farkındalığı Durumlarının Değerlendirilmesi". Sağlık Bilimlerinde Eğitim Dergisi, 3 (1), 24-33.

27. Barışkan, H. ve Karakoç Kumsar, A. (2020). "Sağlık bilimleri fakültesi öğrencilerinde abdominal obezite sıklığı ve yeme farkındalık düzeyleri". Koç Üniversitesi Hemşirelikte Eğitim ve Araştırma Dergisi, 17 (2), 162-169.

28. Orbatu, D.S. (2020). "İzmir İli Lise Çă̆ı Çocuklarında Yeme Farkındalığının Değerlendirilmesi". Tepecik Eğitim ve Araştırma Hastanesi Dergisi, 30 (1), 19-27.

29. Boyraz, N.S. (2020). Lise Öğrencilerinde Yeme Farkındalığı ile Olumsuz Beden Konuşmaları ve Sağlık Algısı Arasındaki İlişkinin İncelenmesi ve Etkileyen Faktörler. Yüksek Lisans Tezi, İnönü Üniversitesi Sağlık Bilimleri Enstitüsü, Malatya.

30. Çakaroğlu, D, Ömür, E.H. ve Arslan, C. (2020). "Üniversite Öğrencilerinin Yeme Tutumu, Yeme Farkındalığı ve Sosyal Görünüș Kaygısının Değerlendirilmesi". Beden Eğitimi ve Spor Bilimleri Dergisi, 14 (1), 1-12.

31. Köse, G. and Çıplak, E. (2020). "Mindful Eating Questionnaired Eating Control, Emotional Eating and Conscious Nutrition Trio". Progress in Nutrition, 22 (2).

32. Saygın, D.G. (2021). Üniversite Öğrencilerinin Yeme Farkındalığı ve Etkileyen Faktörlerin Belirlenmesi: Sağlık Bilimleri Fakültesi Örneği. Yüksek Lisans Tezi, Aydın Adnan Menderes Üniversitesi Sağlık Bilimleri Enstitüsü, Aydın.

33. Özkan, N. and Bilici, S. (2021). "Are Anthropometric Measurements An Indicator of Intuitive and Mindful Eating?". Eating and Weight Disorders-Studies on Anorexia, Bulimia and Obesity, 26 (2), 639-648.

34. Kes, D. and Can Cicek, S. (2021). "Mindful Eating, Obesity and Risk of Type 2 Diabetes in University Students: A CrossSectional Study". Nursing Forum, 6 (1), 1-7.

35. Demirer, B. and Yardımc1, H. (2021). "Is Mindful Eating Higher in Individuals With Orthorexia Nervosa?: A Cross-Sectional Study". Research Square, 5 (2), 1-13.

36. Uçar, A. ve Türker, P.F. (2021). "Lise Öğrencilerinde Hedonik Açlık ve Yeme Farkındalığının Beslenme Durumu ile İlişkisi". 
Başkent Üniversitesi Sağlık Bilimleri Fakültesi Dergisi, 6 (2), $165-178$

37. Petticrew, M. and Roberts, H. (2008). Systematic Reviews in the Social Sciences: A Practical Guide. Oxford: Blackwell Publishing.

38. Higgins, J.P.T, Thompson, S.G, Deeks, J.J. and Altman, D.G (2003). "Measuring Inconsistency in Meta-Analyses". British Medical Journal, 327 (7414), 557-560.

39. Cohen, J. (1988). Statistical Power Analysis for the Behavioral Sciences. New Jersey: Lawrence Erlbaum Associates Publishers. 